Research Article

\title{
Experimental Investigation of Cement/Soda Residue for Solidification/Stabilization of Cr-Contaminated Soils
}

\author{
Fusheng Zha, ${ }^{1}$ Fanghua Zhu, ${ }^{1}$ Bo Kang $\mathbb{D},{ }^{1}$ Long Xu, ${ }^{1}$ Yongfeng Deng $\left(\mathbb{D},{ }^{2}\right.$ Chengbin Yang, \\ and Chengfu Chu'
}

${ }^{1}$ School of Resources and Environmental Engineering, Hefei University of Technology, Hefei 230009, China

${ }^{2}$ Institute of Geotechnical Engineering, Southeast University, Nanjing 210096, China

Correspondence should be addressed to Bo Kang; kangbo@hfut.edu.cn

Received 24 April 2020; Revised 21 June 2020; Accepted 29 June 2020; Published 25 July 2020

Academic Editor: Jia-wen Zhou

Copyright (C) 2020 Fusheng Zha et al. This is an open access article distributed under the Creative Commons Attribution License, which permits unrestricted use, distribution, and reproduction in any medium, provided the original work is properly cited.

\begin{abstract}
Adopting more efficient and sustainable remediation materials is of great importance for the development of solidification and stabilization (S/S) technology. Among them, soda residue could be considered as a desirable binder due to its strong adsorption for heavy metals. For understanding of the performance of Cr-contaminated soils treated by cement/soda residue, the strength, leaching and microstructural characteristics, and the long-term effectiveness under wetting-drying cycles were comprehensively investigated in this study. The results showed that the unconfined compressive strength (UCS) increased and the leached $\mathrm{Cr}^{3+}$ concentration decreased with curing time, binder content, and binder ratio. Increasing the soda residue from C6S14 to C6S24 could improve soil strength and reduce leachability of $\mathrm{Cr}^{3+}$, while a reverse trend was presented with increasing initial $\mathrm{Cr}^{3+}$ concentration. With subsequent wetting-drying cycles, the UCS further increased and then decreased; inversely, the leached $\mathrm{Cr}^{3+}$ decreased, followed by an increase of Cr-contaminated soils. For the specimens of C6S14 and C6S24, the maximum UCS of 6.04 MPa and 6.48 MPa was reached; correspondingly, the minimum leached $\mathrm{Cr}^{3+}$ concentration of $2.78 \mathrm{mg} / \mathrm{L}$ and $1.93 \mathrm{mg} / \mathrm{L}$ was reached after 3 wetting-drying cycles, respectively. Microstructure analysis results found that reaction products like calcium silicate hydrate (C-S-H) and ettringite (AFt) increasingly occupied the soil pore space and caused a denser soil structure after 3 wetting-drying cycles, which indicated the long-term effectiveness of contaminated soils treated by cement/soda residue.
\end{abstract}

\section{Introduction}

With rapid industrialization, heavy metal pollution in soils has become a serious environmental problem that not only deteriorates the geotechnical properties of soils and causes geological hazards, but also worsens ecological environment and threatens human health [1-5]. Solidification/stabilization $(\mathrm{S} / \mathrm{S})$ is one of the most desirable techniques for remediation of heavy metal-contaminated soils, which has been extensively applied worldwide due to its convenience and cost-effectiveness [6-10].

In $\mathrm{S} / \mathrm{S}$ technique, cement, fly ash, and other cementitious binders are added to soil or wastes to immobilize and encapsulate heavy metal ions, which have attracted extensive attention during the past decade [11-13]. According to the researches performed by Chen et al. [14], Du et al. [15], and
Zha et al. [16], the UCS of the Pb- and Zn-contaminated soils treated by cement was significantly increased with cement content and curing time. Liu et al. [4] investigated the strength and leaching properties of $\mathrm{Pb}$-contaminated soils solidified/stabilized by high-calcium fly ash. The results showed that adding high-calcium fly ash to the contaminated soils could remarkably improve the soil strength and reduce the leachability of $\mathrm{Pb}^{2+}$. Yin et al. [6] investigated the geotechnical properties of solidification/stabilization of $\mathrm{Pb}$ contaminated soil using cement/rice husk ash. The results showed that although the UCS decreased due to the incorporation of partial rice husk ash, the leachability of $\mathrm{Pb}^{2+}$ significantly reduced in contaminated soils treated with cement/rice husk ash. Based on the toxicity characteristics leaching procedure (TCLP) and semidynamic leaching tests, Singh and Pant [11] studied the leaching behavior of As- 
contaminated alumina remediated by mixed binders of cement, fly ash, calcium hydroxide, and various polymeric materials and concluded that low leachability of $\mathrm{As}^{3+}$ was attributed to the formations of calcite along with precipitate formation of calcium arsenite in the stabilized soils. It is evident that cement mixed with other materials as a new binder has been widely adopted to remediate the heavy metal-contaminated soils. The usage of more efficient and sustainable remediation materials will be of great importance to the theoretical and practical significance for driving the development of the S/S technique.

Soda residue, i.e., white mud, is a waste material generated from the alkali industry. Large amounts of soda residue are disposed of in situ annually, not only requiring a large area of land, but also causing a series of environmental problems. The main compositions of soda residue include calcium oxide, silica, and magnesia, which was extensively used as the filling material for subgrade construction $[17,18]$. The extremely fine particles of soda residue would result in a large specific surface area that exhibits a strong adsorption capacity [18-20]. Moreover, soda residue can potentially be utilized as a source for seawater decalcification due to its high alkalinity [21]. Therefore, recycling and reusing soda residue in geotechnical engineering is of great practical significance. Based on the experimental investigations, Yang et al. [20] found that soda residue could be used as an inorganic binder to stabilize stone chip by reducing the permeability coefficients, promoting frost resistance and decreasing chloride ion leaching. Further study by Liu et al. [13] confirmed that the hydration and pozzolanic reactions would occur in soil with the incorporation of the soda residue, which could effectively reduce the leachability of $\mathrm{Pb}^{2+}$.

In summary, soda residue could be used as a sustainable material in civil engineering, especially in soil remediation. However, the performance of heavy metal-contaminated soil treated by cement/soda residue was rarely reported. Therefore, the strength and leaching characteristics of cement/soda residue solidified/stabilized Cr-contaminated soil were comprehensively investigated in this study. Additionally, the long-term effectiveness of cement/soda solidified/stabilized Cr-contaminated soil under wetting-drying conditions was considered. Simultaneously, microcosmic testing techniques of X-ray diffraction (XRD) and scanning electron microscopy (SEM) were used to determine the reaction mechanism.

\section{Materials and Methods}

2.1. Materials. The tested soils were sampled from a construction site at a depth of 5-6m in Hefei City, Anhui Province, China. Following ASTM standards [22, 23], the basic physical properties were determined and are summarized in Table 1. The main chemical components of the tested soil were analyzed by X-ray fluorescence (XRF) technique, which is listed in Table 2 . The liquid limit and plasticity index of the tested soil were $49.4 \%$ and 24.8 , respectively, which could be classified as low liquid limit clay (CL) according to the Unified Soil Classification System [24]. In addition, the maximum dry density of $1.66 \mathrm{~g} / \mathrm{cm}^{3}$ and the optimal water content of $21.3 \%$ were determined by performing a Proctor compaction test following [25] (Table 1).
Cement/soda residue was used as a binder to treat the Cr-contaminated soils. Ordinary Portland cement (P325) was purchased from Nanjing city, China, and soda residue was obtained from an alkali works in Weifang city, China. The main chemical components of the cement and soda residue are listed in Table 2. $\mathrm{CaO}, \mathrm{SiO}_{2}$, and $\mathrm{Al}_{2} \mathrm{O}_{3}$ were typically detected in the cement, while $\mathrm{CaO}, \mathrm{SiO}_{2}$, and $\mathrm{MgO}$ were mainly detected in the soda residue. The particles size distribution of soda residue presented in Figure 1 was obtained by using a Malvern Mastersizer 2000 laser particle size analyzer. It could be observed that the particle size distribution of soda residue was mainly in the range of $1-10 \mu \mathrm{m}$, which indicated the large specific surface area and strong adsorption of soda residue.

2.2. Specimen Preparation. The soil sample was oven-dried at $105^{\circ} \mathrm{C}$ for $24 \mathrm{~h}$, pulverized, and then passed through a $2 \mathrm{~mm}$ sieve. The $\mathrm{Cr}\left(\mathrm{NO}_{3}\right)_{3} \cdot 9 \mathrm{H}_{2} \mathrm{O}$ was thoroughly dissolved in deionized water and mixed with the soil powder. The $\mathrm{Cr}$ contaminated soil was prepared at the water content corresponding to its liquid limit, then it was sealed in freshkeeping bags and cured for 7 days under standard curing conditions (temperature of $20 \pm 2^{\circ} \mathrm{C}$, relative humidity of $95 \%)$. With reference to the researches carried out by $\mathrm{Du}$ et al. [15], Liu et al. [26], and Liu et al. [27], $\mathrm{Cr}^{3+}$ was added to soil sample chosen for contamination at concentrations of 1000, 5000, and $10000 \mathrm{mg} / \mathrm{kg}$ (denoted Cr0.1, Cr0.5, and Cr1.0 as the mass rations of $\mathrm{Cr}^{3+}$ to dry soil).

After completion of the curing period, the prepared Crcontaminated soil and cement/soda residue were dried, pulverized, and passed through $2 \mathrm{~mm}$ and $0.5 \mathrm{~mm}$ sieves, respectively. Then, the cement/soda residue and contaminated soil powder were mixed and stirred evenly. Specimens were prepared with fixed mass rations of cement/soda residue to dry soils of $20 \%$ and $30 \%$ (called A20 and A30). The binder ratio of cement to soda residue in A20 was designed for C4S16, C6S14, C8S12, and C10S10; corresponding binder rations of C6S24, C9S21, C12S18, and C15S15 were designed in A30. Next, the contaminated soil powders were oven-dried again and mixed thoroughly with the additives at the optimal water content shown in Table 1. Finally, the prepared mixtures were put into a cylindrical mold and statically compacted to obtain specimens with a diameter of $50 \mathrm{~mm}$, height of $50 \mathrm{~mm}$, and dry density of $1.58 \mathrm{~g} / \mathrm{cm}^{3}$ (equaling 95\% of the maximum dry density). The prepared specimens were sealed and cured in a constant temperature and humidity curing box at a controlled temperature of $22 \pm 1{ }^{\circ} \mathrm{C}$ and relative humidity of $95 \pm 2 \%$. Specimens prepared for the UCS and TCLP tests were cured for $7,14,28,56$, and 90 days, while for the wetting-drying cycle tests, they were cured for 90 days.

\subsection{Test Methods}

2.3.1. Unconfined Compressive Strength Test. In accordance with the Standard Test Method for Unconfined Compressive Strength of Cohesive Soil [28], the as-prepared specimen was assembled in the strain-controlled YHS-2 UCS testing 
TABLE 1: Basic physical properties of the tested soil.

\begin{tabular}{lcccccc}
\hline $\begin{array}{l}\text { Density } \\
\left(\mathrm{g} / \mathrm{cm}^{3}\right)\end{array}$ & $\begin{array}{c}\text { Natural water content } \\
(\%)\end{array}$ & $\begin{array}{c}\text { Specific } \\
\text { gravity }\end{array}$ & $\begin{array}{c}\text { Liquid limit } \\
(\%)\end{array}$ & $\begin{array}{c}\text { Plastic limit } \\
(\%)\end{array}$ & $\begin{array}{c}\text { Maximum dry density } \\
\left(\mathrm{g} / \mathrm{cm}^{3}\right)\end{array}$ & $\begin{array}{c}\text { Optimum water content } \\
(\%)\end{array}$ \\
\hline 1.92 & 25.5 & 2.669 & 49.4 & 24.8 & 1.663 & 21.2 \\
\hline
\end{tabular}

TABLE 2: Major chemical components of the tested soil and binders.

\begin{tabular}{ccccccccccc}
\hline \multicolumn{2}{c}{ Chemical composition } & $\mathrm{CaO}$ & $\mathrm{SiO}_{2}$ & $\mathrm{Al}_{2} \mathrm{O}_{3}$ & $\mathrm{SO}_{3}$ & $\mathrm{Fe}_{2} \mathrm{O}_{3}$ & $\mathrm{MgO}$ & $\mathrm{TiO}_{2}$ & $\mathrm{Na}_{2} \mathrm{O}$ & $\mathrm{Others}^{2}$ \\
\hline \multirow{4}{*}{ Content (\%) } & Soil & 0.48 & 54.63 & 21.56 & - & 17.19 & 1.77 & 1.99 & 0.65 & 1.73 \\
& Cement & 43.80 & 27.21 & 9.90 & 3.01 & 2.88 & 1.57 & 0.47 & 0.44 & 1.85 \\
& Soda residue & 62.81 & 10.20 & 9.00 & 0.30 & 1.31 & 12.50 & 0.24 & 0.23 & 3.20 \\
\hline
\end{tabular}

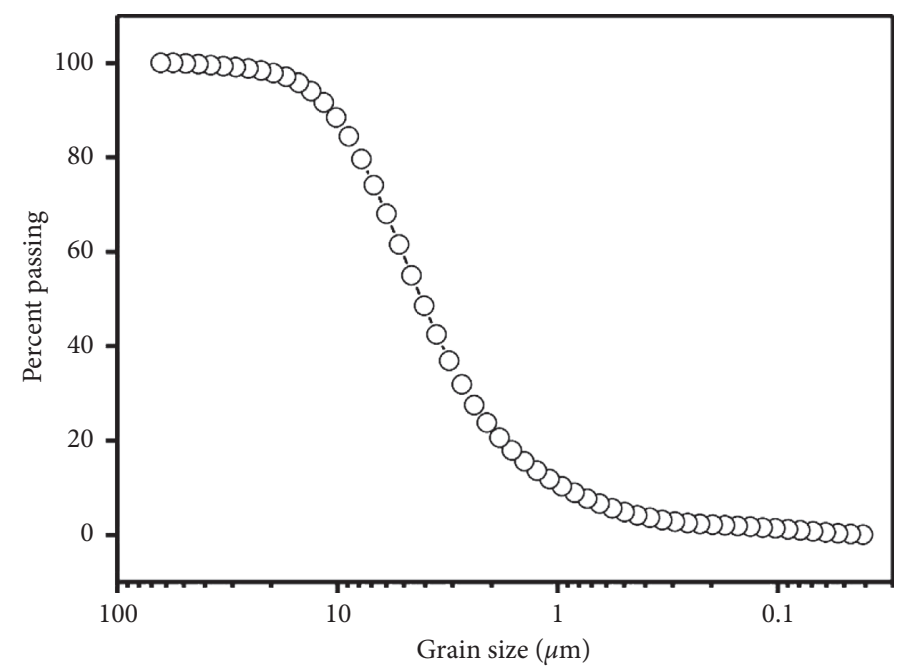

Figure 1: Curve of particle size distribution of soda residue.

apparatus. The UCS test was then performed at a vertical strain rate of $1 \% \mathrm{~min}$. The stress and strain of the specimen were recorded at intervals of $5 \mathrm{~s}$ until the specimen failed.

2.3.2. Toxicity Characteristic Leaching Procedure Test. The leaching characteristic of the solidified contaminated specimen was determined using the toxicity characteristic leaching procedure (TCLP) following USEPA, Method 1311 1994 [29]. The prepared specimen was pulverized into pieces smaller than $9.5 \mathrm{~mm}$. A leachant with $\mathrm{pH}$ value of $2.88 \pm 0.05$ was prepared by diluting $5.7 \mathrm{~mL}$ acetic acid (HAc) in $1 \mathrm{~L}$ deionized water. Then, $12.5 \mathrm{~g}$ of crushed samples and $250 \mathrm{~mL}$ leachant (solid-to-liquid ratio of $1: 20$ ) were mixed in a polythene bottle and vibrated at $80 \mathrm{rpm}$ for $18 \mathrm{~h}$. The leachate was then filtered through a $0.45 \mu \mathrm{m}$ filter membrane, and then the concentration of $\mathrm{Cr}^{3+}$ in the leachate was determined by atomic absorption spectrophotometry (AAS).

2.3.3. Cyclic Wetting-Drying Test. The wetting-drying test was conducted on the specimens of C6S14 and C6S24 with Cr0.5 according to ASTM D4843-88 [30]. The specimens were placed in an oven maintained at $45 \pm 3^{\circ} \mathrm{C}$ for $24 \mathrm{~h}$; then the specimens were removed and left to stand for $1-2 \mathrm{~h}$ to reach room temperature of $22 \pm 3^{\circ} \mathrm{C}$. Then, the specimen was placed in water tanks and immersed in water at temperature of $20 \pm 3^{\circ} \mathrm{C}$ for $23 \mathrm{~h}$. Finally, loose particles attached on the surface of the specimen were removed; the water in the tanks drained out. And then, the specimen was placed at room temperature for $1 \mathrm{~h}$. The whole process was one wetting-drying cycle. In this study, the number of wetting-drying cycles was designed as $0,3,5,10$, and 20 . After $0,3,5,10$, and 20 wetting-drying cycles, the UCS and TCLP tests were conducted following the respective procedures specified above.

The mass loss tests were carried out on the specimen during 20 wetting-drying cycles. After completion of each cycle, the change in mass loss of specimen was measured by electronic balance. Consequently, the cumulative mass loss rate could be determined using the following equation:

$$
C=\sum \frac{M_{i}}{M_{0}} \times 100 \%, \quad(i=1,2,3 \ldots 20)
$$

where $C(\%)$ is the cumulative mass loss of specimen after $i$ wetting-drying cycles, $M_{i}(\mathrm{~g})$ is the dry mass loss of specimen under $i$ wetting-drying cycle, and $M_{0}(\mathrm{~g})$ is the initial dry mass of the specimen. When the $C$ value exceeds $30 \%$ or the specimen is broken during testing, the procedure is stopped [30]. 
2.3.4. Microstructure Analysis. After 0, 3, and 10 wettingdrying cycles, the specimens of C6S24 with Cr0.5 were freeze-dried for microstructural characteristics test. The $\mathrm{XRD}$ tests were carried out with $\mathrm{Cu}-\mathrm{K} \alpha$ radiation on a Rigaku D/Max-2005 V instrument. The peaks and crystalline phases were identified by JADE 6.5 software. SEM analysis was performed on the specimens using a JSM-6490LV scanning electron microscope. The specimens were broken into small pieces with an approximate size of $5 \mathrm{~mm} \times 5 \mathrm{~mm} \times 5 \mathrm{~mm}$, freeze-dried in a lyophilizer, and finally pretreated using vacuum metal spraying technology to obtain sufficient conductivity.

\section{Results and Discussion}

3.1. Unconfined Compressive Strength. Evolutions of the UCS with curing time of the stabilized Cr-contaminated soils are presented in Figure 2. As shown in Figure 2, the UCS of stabilized soils significantly increased followed by a lesser degree of increase with curing time. It was obvious that the UCS of stabilized soils cured for 7 days higher than $0.35 \mathrm{MPa}$, which met the United States' strength requirement for landfill treatment [31]. While for the stabilized soil with Cr0.1 and Cr0.5, the UCS exceeded $1 \mathrm{MPa}$, which satisfied France's criteria for the deposit of stabilized waste in hazardous waste landfills [32]. It could also be observed from Figures 2(a)-2(c) that, as the initial $\mathrm{Cr}^{3+}$ concentration increased, the UCS of stabilized soil significantly decreased, especially for soils with Cr0.1.

Evolutions of the UCS with binder ratio of the stabilized Cr-contaminated soils are presented in Figure 3. As shown in Figure 3, it was obvious that the UCS of Cr-contaminated soils significantly increased as cement/soda residue increased from A20 to A30. With increasing binder ratio of cement to soda residue, the UCS gradually increased in $\mathrm{Cr}$ contaminated soils. For further analysis of the effect of soda residue on the UCS of Cr-contaminated soil, results of the UCS with C6S14 and C6S24 curing for 90 days are presented in Figure 4. Curves in Figure 4 evidently show that the UCS of the $\mathrm{Cr}$-contaminated soils increased with the increase of soda residue. Particularly, for the soil with Cr0.1 and Cr0.5, when the soda residue increased from C6S14 to C6S24, the UCS increased by $38 \%$ and $36 \%$, respectively.

The increase of UCS contaminated soil was attributed to the hydration reaction between the soil and cement/soda residue, which resulted in the formed large amount of C-S$\mathrm{H}$, calcium aluminate hydrate $(\mathrm{C}-\mathrm{A}-\mathrm{H}), \mathrm{AFt}$, and $\mathrm{Ca}(\mathrm{OH})_{2}$. These hydration products will cement and encapsulate the soil particles and occupy the pore space, thereby improving the soil strength [33-35]. Additionally, the pozzolanic reactions between the $\mathrm{SiO}_{2}, \mathrm{Al}_{2} \mathrm{O}_{3}$, and $\mathrm{Ca}^{2+}$ will occur in soil and further promote the formation of C-S-H, C-A-H, and other cementitious hydrates [36]. According to the study performed by Zha et al. [34], the pozzolanic reaction will be strengthened in the alkaline environment provided by the soda residue and previous reactions. Moreover, the improvement of soil strength may be due to the generation of insoluble $\mathrm{Ca}-\mathrm{Cr}$ oxides and hydroxide nitrate complexes precipitation in alkaline environment $[36,37]$. According to the researches performed by Kindness et al. [38], Macias et al. [39], and Jing et al. [40], the precipitation of $\mathrm{Ca}_{2} \mathrm{Cr}_{2} \mathrm{O}_{5} \cdot 6 \mathrm{H}_{2} \mathrm{O}$ could be generated in highly alkaline environment. Further study by Chen et al. [41] reported that $\mathrm{Cr}^{3+}$ could react with calcium hydroxide to form $\mathrm{Ca}_{2} \mathrm{Cr}(\mathrm{OH})_{7} \cdot 3 \mathrm{H}_{2} \mathrm{O}$ precipitates, which played a role in increasing the soil strength. In this study, the main components of $\mathrm{CaCO}_{3}$ and $\mathrm{CaSO}_{4}$ in the soda residue could also constitute the soil's skeleton to increase the soil strength. With increasing curing time, binder content, and binder ratio, these physicochemical reactions will continuously develop in the $\mathrm{S} / \mathrm{S}$ process and create more hydration gels and insoluble Cr precipitations, thus leading to the notable increase in UCS of stabilized soils in the initial curing period. However, the physicochemical reactions will gradually fade, and the various microstructures of soil will tend to be constant with curing time. In the meantime, the pozzolanic reactions will be retarded due to the limited pozzolanic components in the soda residue as shown in Table 2. Furthermore, the existence and increase of $\mathrm{Cr}^{3+}$ in soils hindered the hydration reaction of cement/soda residue, which will decrease the formation of hydration products [42, 43].

3.2. Leaching Characteristics. Evolutions of leached $\mathrm{Cr}^{3+}$ concentration with curing time of stabilized Cr-contaminated soils are presented in Figure 5. As shown in Figure 5, the leached $\mathrm{Cr}^{3+}$ concentration dramatically decreased followed by a lesser degree of decrease with further increase of curing time, which indicated the significant effect of cement/ soda residue on the leachability of $\mathrm{Cr}^{3+}$. For the stabilized soils with $\mathrm{Cr} 0.1$, the leached $\mathrm{Cr}^{3+}$ concentrations of soil with curing time were all below $5 \mathrm{mg} / \mathrm{L}$, which satisfied the US EPA's evaluation criteria for the remediation of waste sites [29]. While for the stabilized soils with Cr0.5 and Cr1.0, the leached $\mathrm{Cr}^{3+}$ concentrations of soil were below the regulatory limit of $5 \mathrm{mg} / \mathrm{L}$ after curing for 28 days. It could also be observed from Figures 5(a)-5(c) that, as the initial $\mathrm{Cr}^{3+}$ concentration increased, the leached $\mathrm{Cr}^{3+}$ concentration significantly increased, especially in stabilized soil with Cr0.5 and Cr1.0.

Evolutions of the leached $\mathrm{Cr}^{3+}$ concentration with binder ration of the stabilized $\mathrm{Cr}$-contaminated soils are presented in Figure 6. As shown in Figure 6, it was evident that the leached $\mathrm{Cr}^{3+}$ concentration of soils decreased with cement/ soda residue increased from A20 to A30. With increasing binder ratio of cement to soda residue, the leached $\mathrm{Cr}^{3+}$ concentration gradually decreased of $\mathrm{Cr}$-contaminated soils. For further analysis of effect of soda residue on the leaching characteristics of $\mathrm{Cr}$-contaminated soil, results of the leached $\mathrm{Cr}^{3+}$ concentrations with C6S14 and C6S24 curing for 90 days are presented in Figure 7. As shown in Figure 7, the leached $\mathrm{Cr}^{3+}$ concentration of the contaminated soils decreased as the soda residue content increased from C6S14 to C6S24. For the soil with Cr0.1, Cr0.5, and Cr1.0, when soda residue increased from C6S14 to C6S24, the leached $\mathrm{Cr}^{3+}$ concentration decreased by $53 \%, 12 \%$, and $5 \%$, respectively, which indicated the significant immobilization effectiveness on $\mathrm{Cr}^{3+}$ with lower initial concentration. 


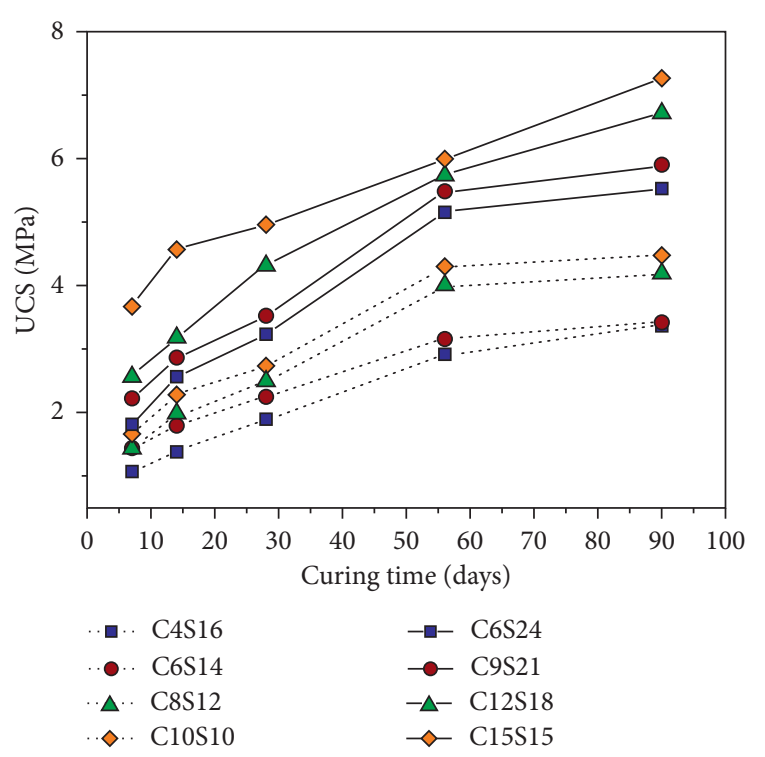

(a)

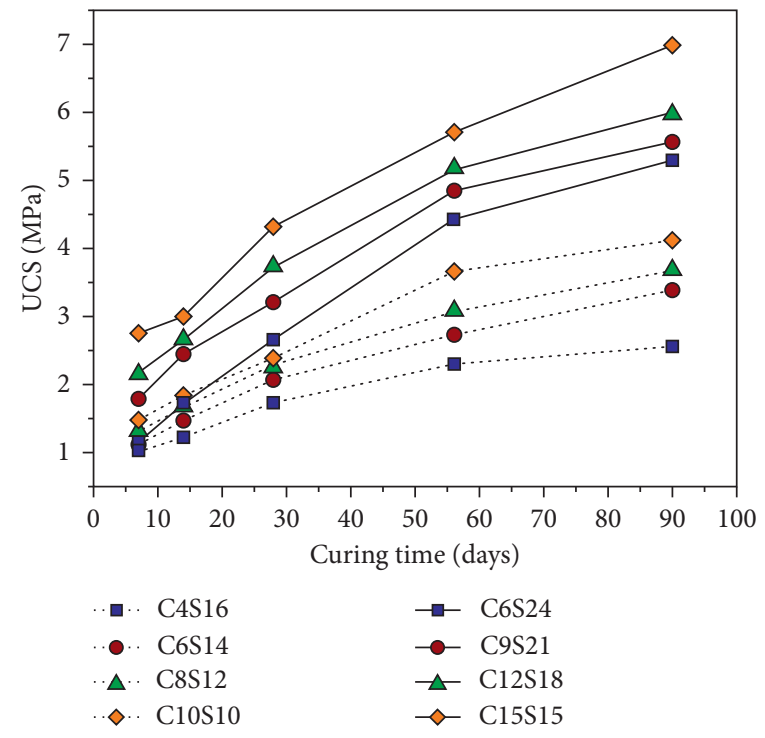

(b)

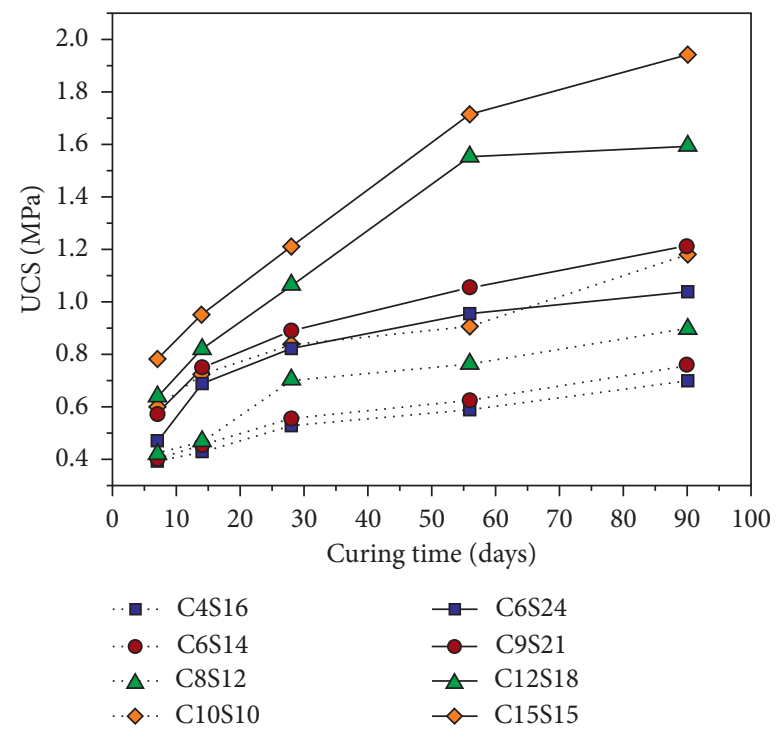

(c)

Figure 2: Evolutions of UCS with curing time of the stabilized Cr-contaminated soils: (a) Cr0.1, (b) Cr0.5, and (c) Cr1.0.

This was because a large amount of C-S-H, C-A-H, AFt, and other hydration gels were formed because of hydration and pozzolanic reactions, which had considerable specific surface area to effectively adsorb $\mathrm{Cr}^{3+}[11,44]$. The pozzolanic reaction of cement/soda residue will be improved by the soda residue-induced highly alkaline environment in soils. Additionally, in the $\mathrm{S} / \mathrm{S}$ process, the $\mathrm{Cr}^{3+}$ could replace $\mathrm{Si}^{2+}, \mathrm{Ca}^{2+}, \mathrm{Al}^{3+}$ in C-S-H and $\mathrm{Al}^{3+}, \mathrm{Fe}^{3+}$ in C-A-H, and $\mathrm{Al}^{3+}$ in AFt, which immobilized $\mathrm{Cr}^{3+}$ in the soil $[37,43,45]$. Moreover, the reduced leachability of $\mathrm{Cr}^{3+}$ might be attributed to $\mathrm{Cr}^{3+}$ existing as the precipitation of $\mathrm{Ca}_{2} \mathrm{Cr}_{2} \mathrm{O}_{5} \cdot 6 \mathrm{H}_{2} \mathrm{O}$ and $\mathrm{Ca}_{2} \mathrm{Cr}(\mathrm{OH})_{7} \cdot 3 \mathrm{H}_{2} \mathrm{O}$ in contaminated soil [36-41]. In this study, the incorporation of soda residue in soils could exhibit strong adsorption capacity for $\mathrm{Cr}^{3+}$ due to its extremely fine particle size and large specific surface area [18-20]. With the increase of curing time, binder content, and binder ratio, these physicochemical reactions will proceed and continuously generate more hydration products and $\mathrm{Cr}$ precipitations, which significantly decreased the leachability of $\mathrm{Cr}^{3+}$ in the initial curing period. However, the physicochemical reactions will gradually fade with curing time and the existence and increase of $\mathrm{Cr}^{3+}$ in soils will hinder hydration reaction of cement/soda residue as well, which result in the limited immobilization of $\mathrm{Cr}^{3+}$ in 

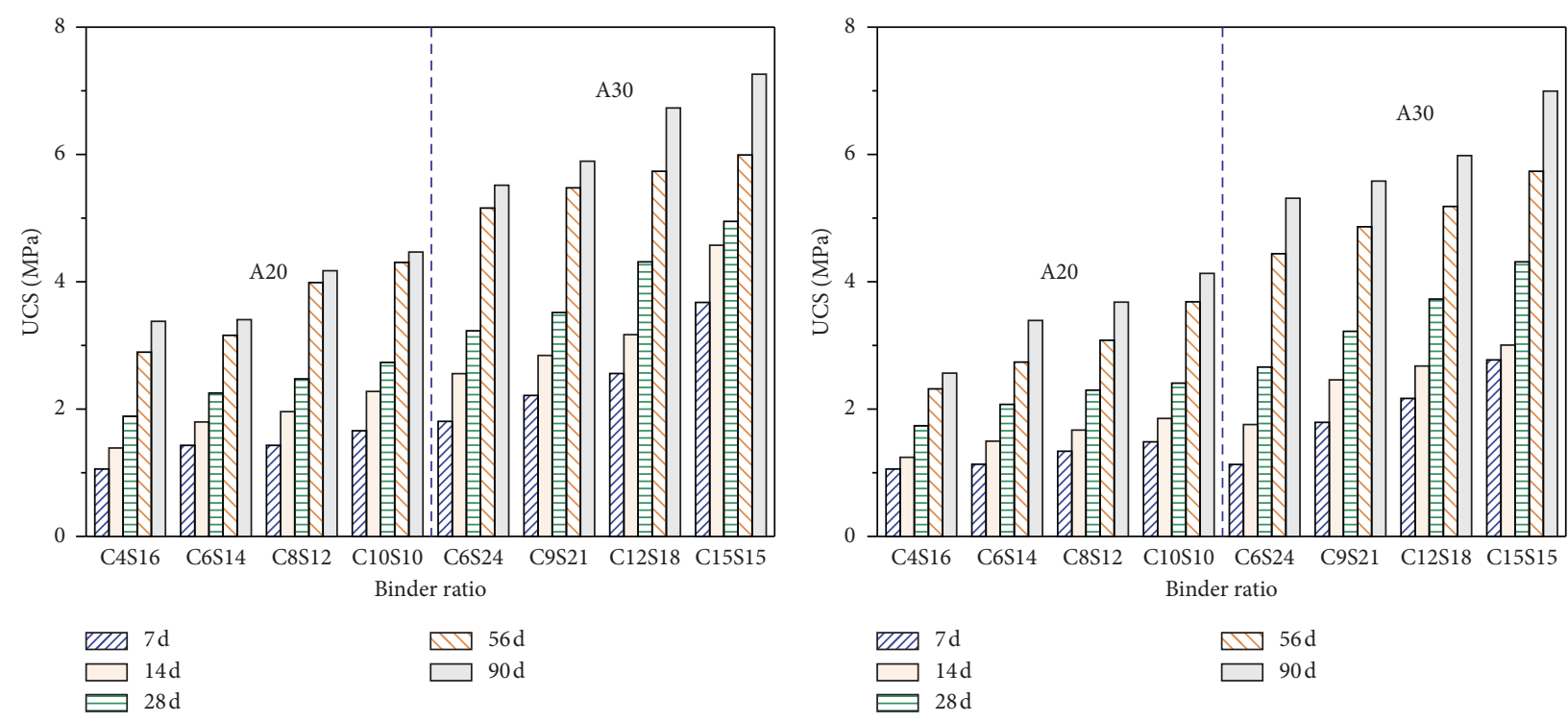

(a)

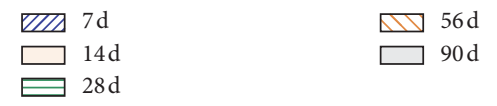

(b)

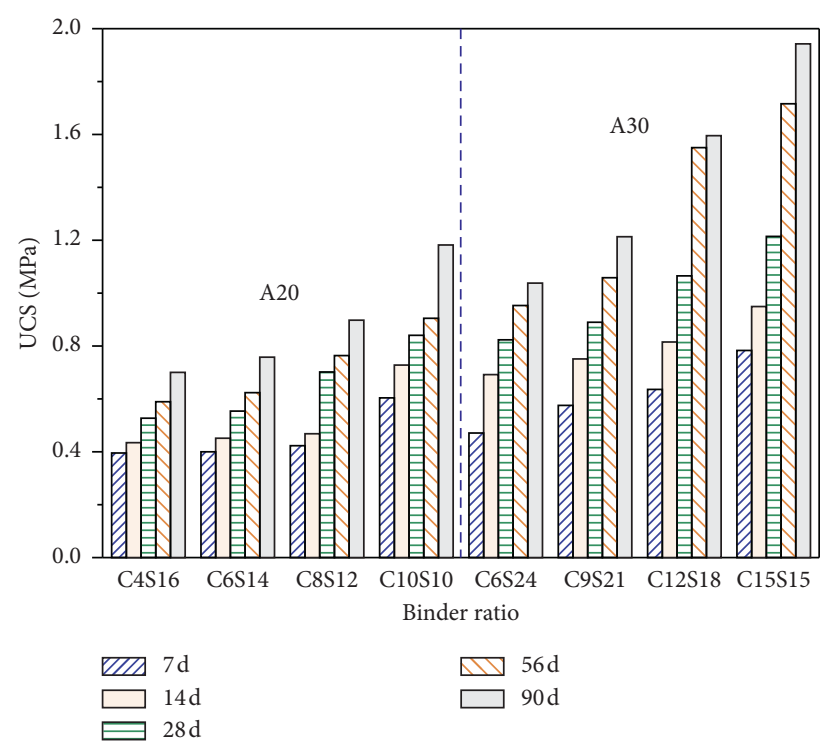

(c)

FIgure 3: Evolutions of the UCS with binder ratio of the stabilized Cr-contaminated soils: (a) Cr0.1, (b) Cr0.5, and (c) Cr1.0.

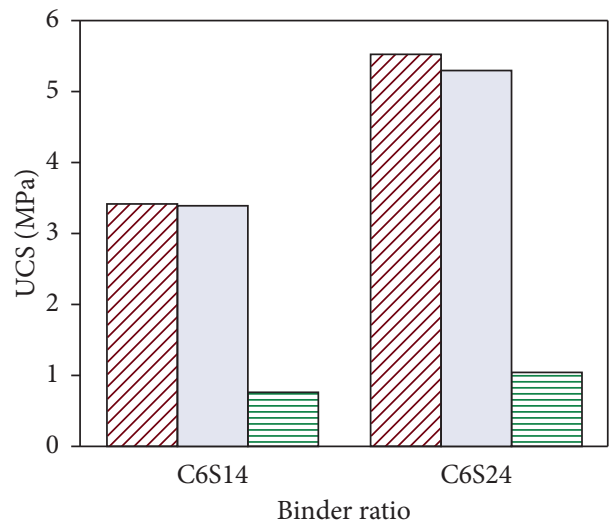

EZA $1000 \mathrm{mg} / \mathrm{L}$

$5000 \mathrm{mg} / \mathrm{L}$

$10000 \mathrm{mg} / \mathrm{L}$

FIGURE 4: Relationship between the UCS and soda residue content of the stabilized Cr-contaminated soils. 


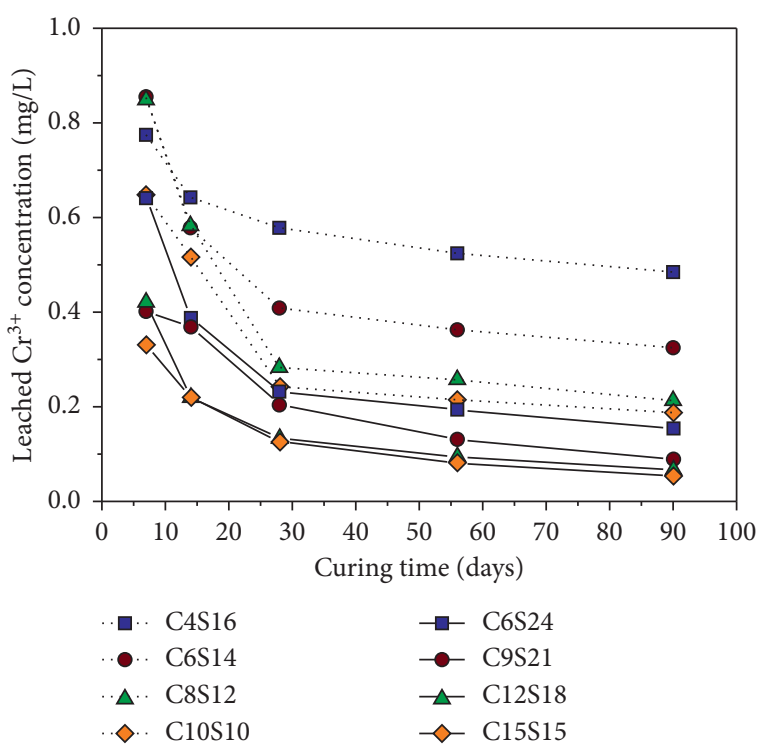

(a)

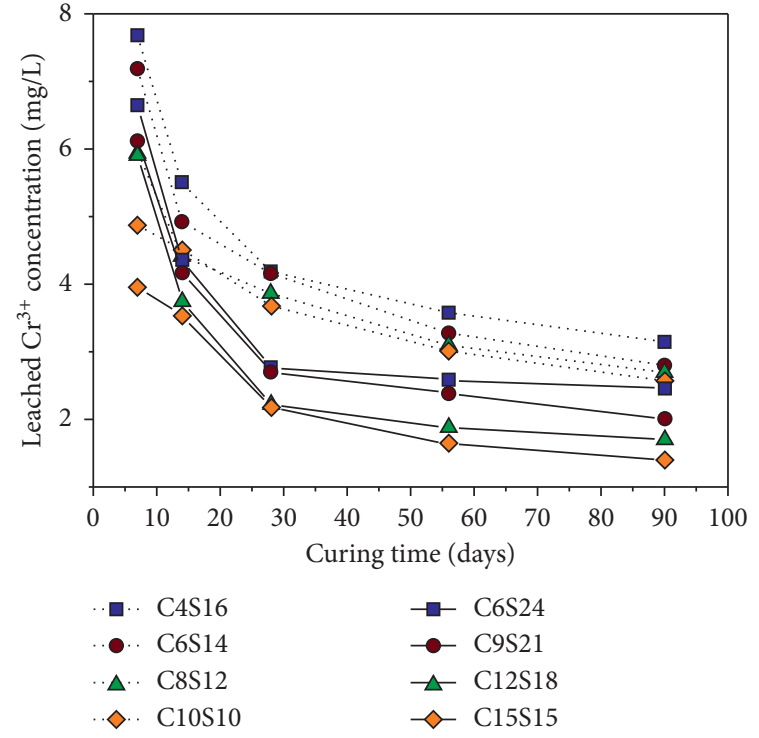

(b)

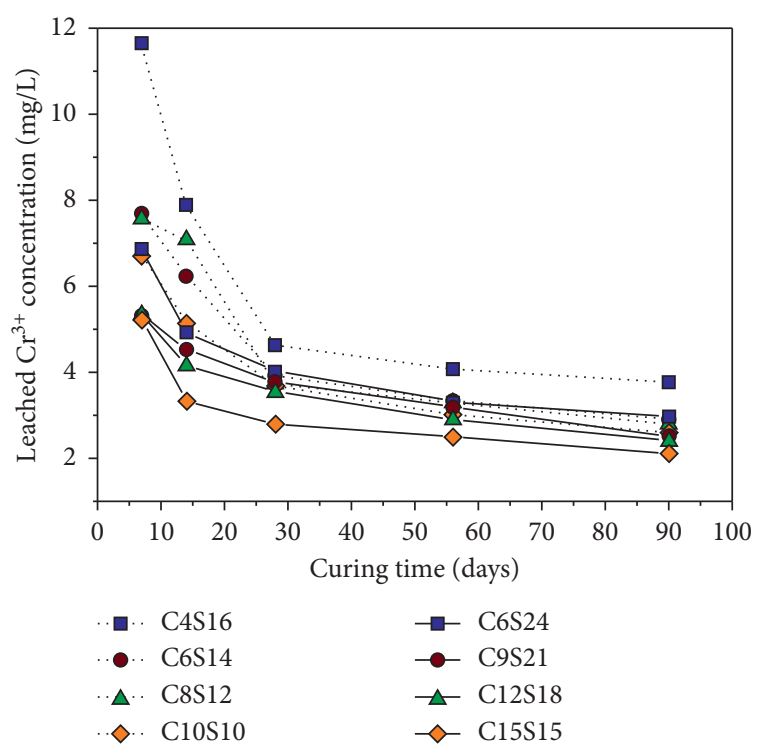

(c)

Figure 5: Evolutions of leached $\mathrm{Cr}^{3+}$ concentration with curing time of stabilized Cr-contaminated soils: (a) Cr0.1, (b) Cr0.5, and (c) Cr1.0.

contaminated soils $[42,43]$. In the meantime, the pozzolanic reactions will be retarded due to the limited pozzolanic components in the soda residue as shown in Table 2.

\subsection{Wetting-Drying Cycles}

3.3.1. Effect of Cyclic Wetting-Drying on the UCS. For investigation of long-term effectiveness of $\mathrm{Cr}$-contaminated soils solidified/stabilized by cement/soda residue, the results of influence of wetting-drying cycles on the UCS, accompanied with trends in the cumulative mass loss rate are presented in Figures 8 and 9, respectively.
As shown in Figure 8, the UCS of stabilized Cr-contaminated soils increased and followed by a decrease with increasing wetting-drying cycles. For the specimen of C6S14 and C6S24, the maximum UCS of $6.04 \mathrm{MPa}$ and $6.48 \mathrm{MPa}$ could be reached after 3 wetting-drying cycles, respectively. The UCS of stabilized soils larger than $0.35 \mathrm{MPa}$ after 20 wetting-drying cycles could also be observed, which satisfied the United States' strength standards for the remediation of landfills [31]. Curves in Figure 9 show that the cumulative mass loss rate gradually increased with wetting-drying cycles. A relatively stable cumulative mass loss rate could be observed during 0-3 wetting-drying cycles, which could 


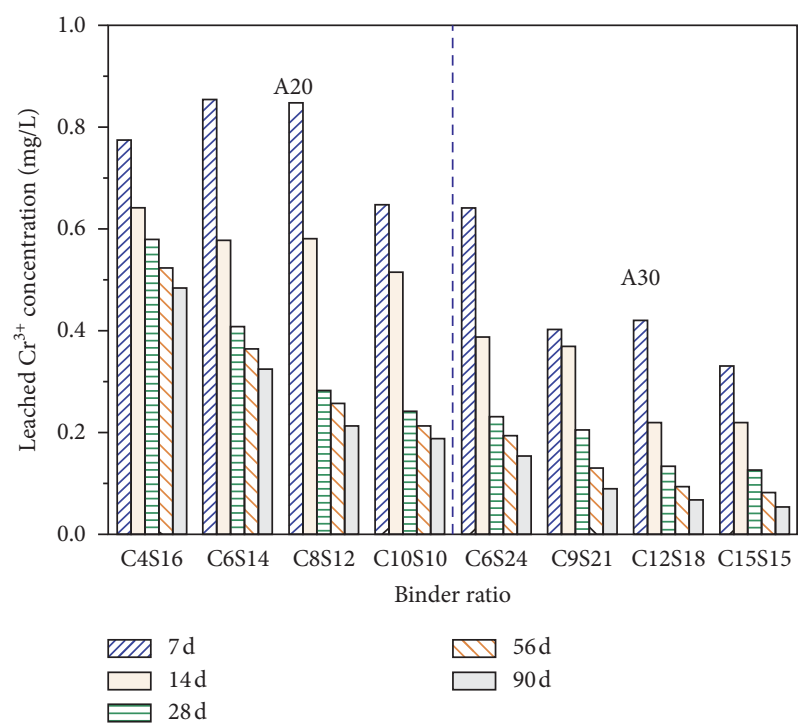

(a)

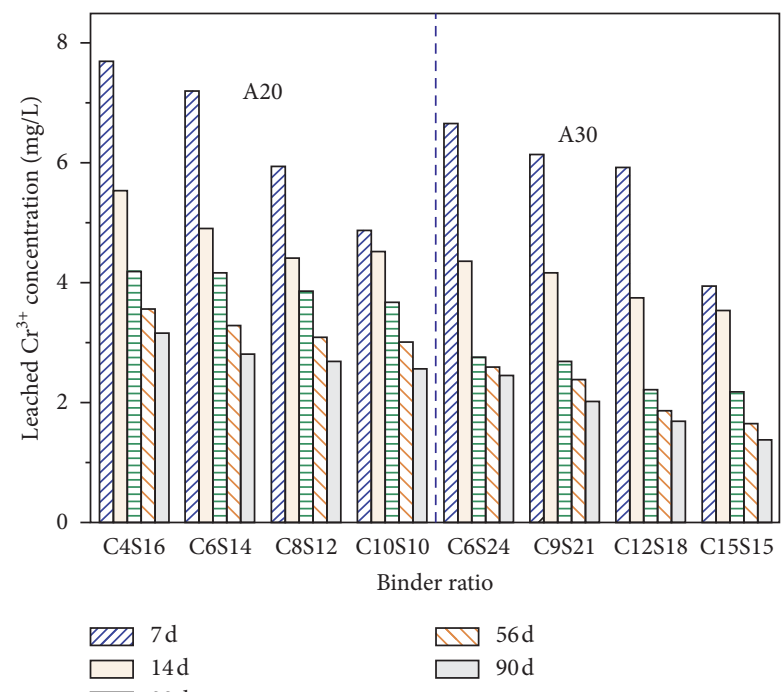

(b)

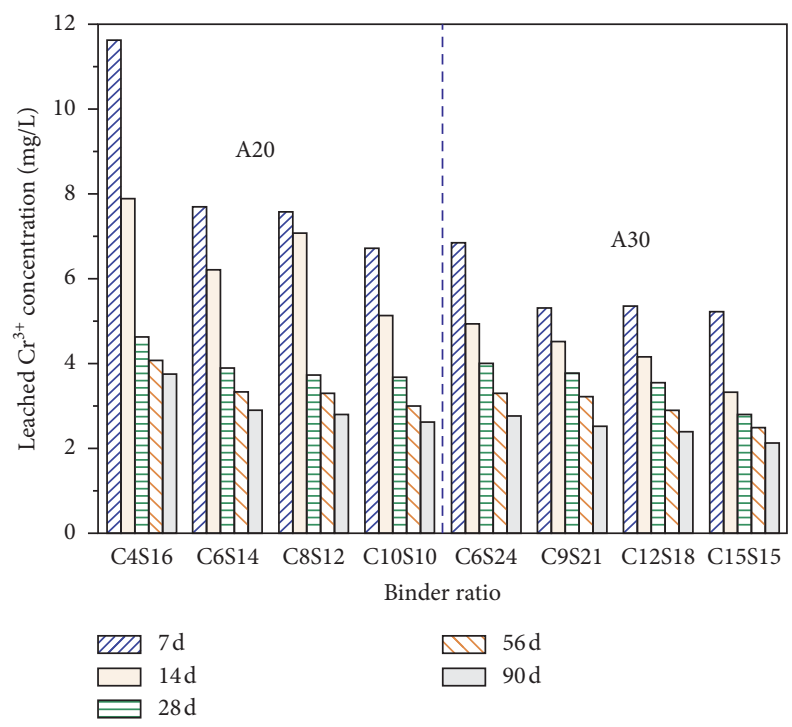

(c)

Figure 6: Evolutions of the leached $\mathrm{Cr}^{3+}$ concentration with binder ration of the stabilized Cr-contaminated soils: (a) Cr0.1, (b) Cr0.5, and (c) Cr1.0.

support the results shown in Figure 8. These results indicated that cement/soda residue could perform a long-term effectiveness on the remediation of $\mathrm{Cr}$-contaminated soils under wetting-drying cycle environment.

This was because, in the early stages of wetting-drying cycles, the hydration and pozzolanic reactions were still uncompleted and continuously generated hydration gels like C-S-H and C-A-H, leading to further increase in the UCS of contaminated soils. Similar results were reported by Zha et al. [34] in solidification/stabilization of contaminated soils using fly ash. Additionally, the more formed insoluble $\mathrm{Ca}-\mathrm{Cr}$ oxides and hydroxide nitrate complexes precipitation like $\mathrm{Ca}_{2} \mathrm{Cr}_{2} \mathrm{O}_{5} \cdot 6 \mathrm{H}_{2} \mathrm{O}$ and $\mathrm{Ca}_{2} \mathrm{Cr}(\mathrm{OH})_{7} \cdot 3 \mathrm{H}_{2} \mathrm{O}$ could improve the contaminated soils strength as well [36-41]. However, these physicochemical reactions between the soil and cement/soda residue gradually completed with the increase of wetting-drying cycles. The integrity of the stabilized Cr-contaminated soils will be weakened, soil structure will be destroyed, and microfractures will continue to generate and expand [34]. Additionally, the reactions product of AFt could cause significant swelling in contact with water, and soluble salts such as $\mathrm{CaCl}_{2}$ and $\mathrm{NaCl}$ in soils will dissolve out, which lead to the deterioration of the UCS of stabilized soils $[36,46]$.

3.3.2. Effect of Cyclic Wetting-Drying on Leaching Characteristics. Evolutions of leached $\mathrm{Cr}^{3+}$ concentration of stabilized contaminated soils with wetting-drying cycles are presented in Figure 10. 


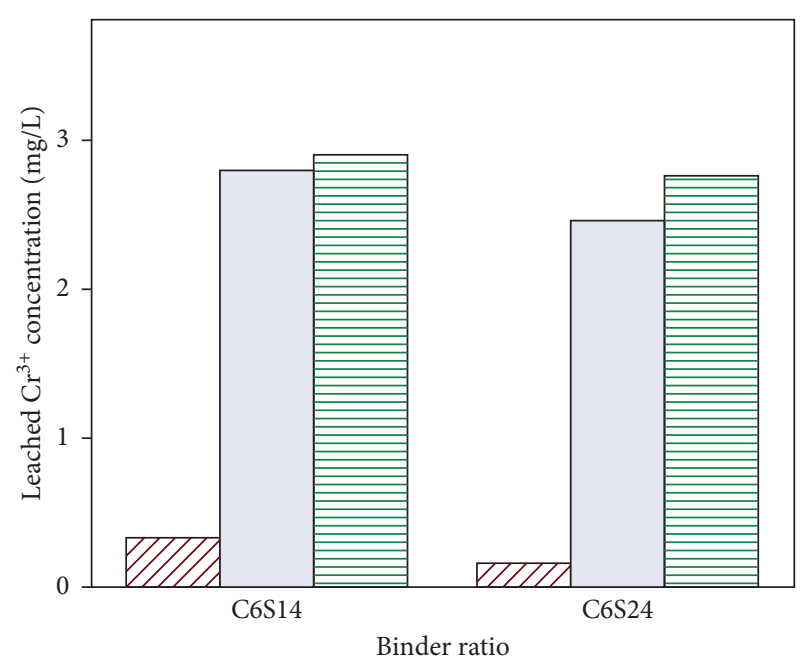

ZI/ $1000 \mathrm{mg} / \mathrm{L}$ $5000 \mathrm{mg} / \mathrm{L}$ $10000 \mathrm{mg} / \mathrm{L}$

Figure 7: Relationship between the leached $\mathrm{Cr}^{3+}$ concentration and soda residue content of the stabilized Cr-contaminated soils.

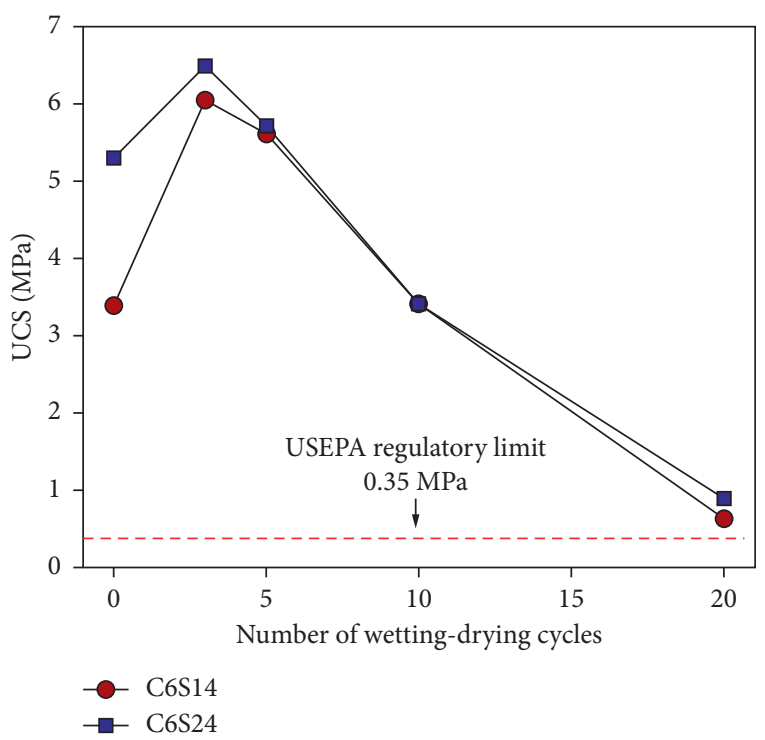

FIGURE 8: Evolutions of the UCS with wetting-drying cycles of the stabilized $\mathrm{Cr}$-contaminated soils.

As shown in Figure 10, the leached $\mathrm{Cr}^{3+}$ concentration decreased and followed by an increase with wetting-drying cycles. For the specimens of C6S14 and C6S24, the minimum leached $\mathrm{Cr}^{3+}$ concentration of $2.78 \mathrm{mg} / \mathrm{L}$ and $1.93 \mathrm{mg} /$ $\mathrm{L}$ could be reached after 3 wetting-drying cycles, respectively. It could also be observed that the leached $\mathrm{Cr}^{3+}$ concentration of stabilized soils below $5 \mathrm{mg} / \mathrm{L}$ after 0,3 , and 5 wetting-drying cycles, which satisfied the US EPA's evaluation criteria for the remediation of waste sites [29]. Therefore, it could be concluded that cement/soda residue had long-term effectiveness on stabilized Cr-contaminated soils under cyclic wetting and drying environment.

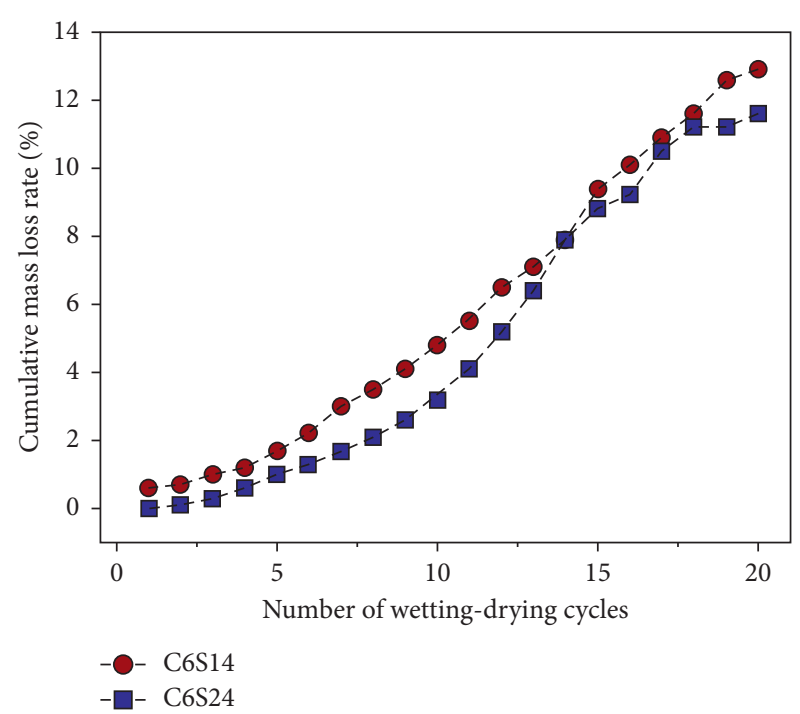

FIGURE 9: Evolutions of the cumulative mass loss rate with wettingdrying cycles of stabilized Cr-contaminated soils.

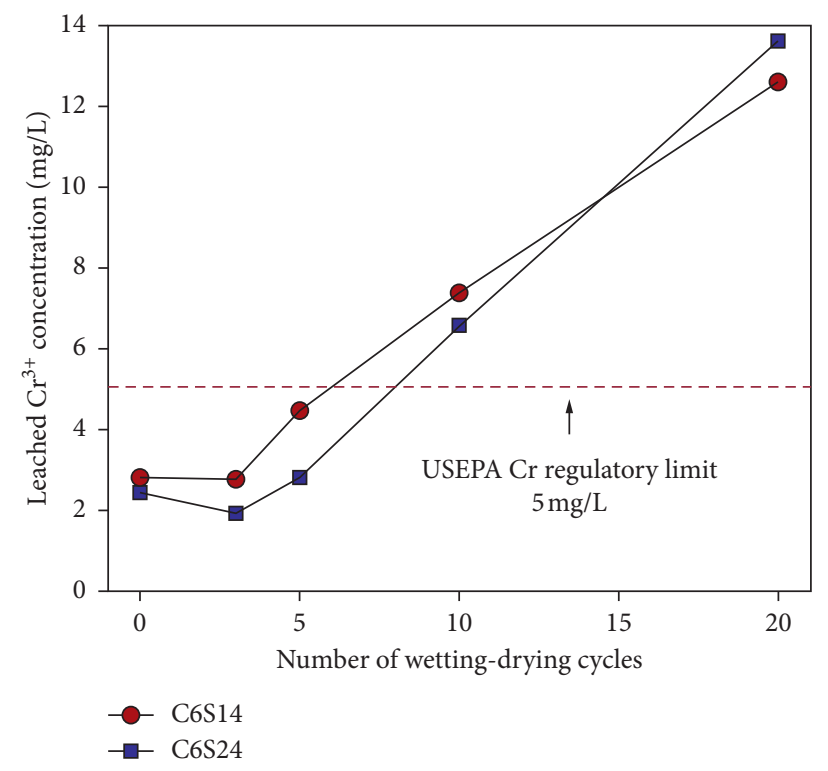

FIgURE 10: Evolutions of the leached $\mathrm{Cr}^{3+}$ concentration with wetting-drying cycles of stabilized Cr-contaminated soils.

These results were mainly attributed to the hydration and pozzolanic reactions proceeded in the initial wettingdrying cycles. The generated hydration gels, such as C-S-H, $\mathrm{C}-\mathrm{A}-\mathrm{H}$, and AFt, could further immobilize $\mathrm{Cr}^{3+}$ in stabilized soils. Additionally, the more $\mathrm{Cr}^{3+}$ could exist as insoluble $\mathrm{Ca}-\mathrm{Cr}$ oxides and hydroxide nitrate complexes precipitation like $\mathrm{Ca}_{2} \mathrm{Cr}_{2} \mathrm{O}_{5} \cdot 6 \mathrm{H}_{2} \mathrm{O}$ and $\mathrm{Ca}_{2} \mathrm{Cr}(\mathrm{OH})_{7} \cdot 3 \mathrm{H}_{2} \mathrm{O}$, which reduced its leachability in soils [36-41]. However, with wettingdrying cycles increasing, these physicochemical reactions will fully finish in stabilized soils. Additionally, the reactions product of AFt could cause significant swelling in contact 


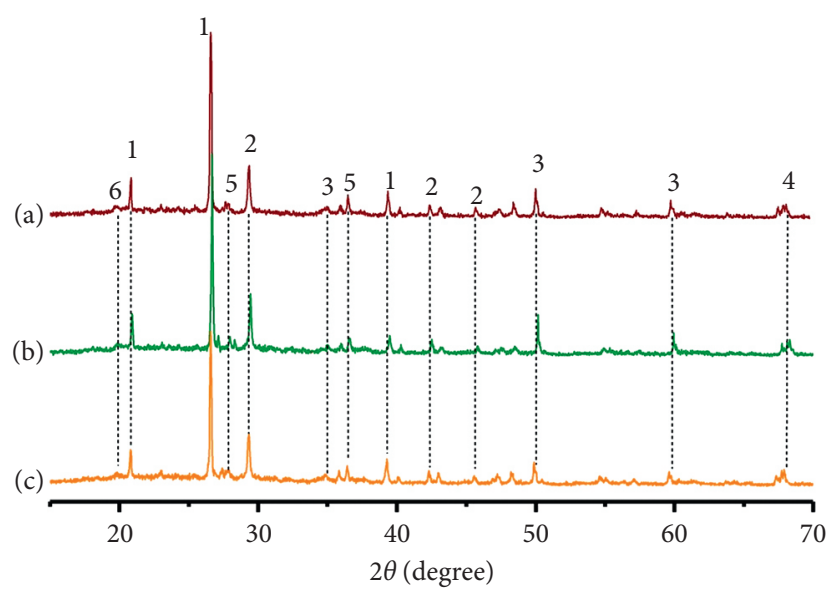
(1) Quartz
(4) C-A-H
(2) C-S-H
(5) $\mathrm{Ca}_{2} \mathrm{Cr}(\mathrm{OH})_{7} \cdot 3 \mathrm{H}_{2} \mathrm{O}$
(3) $\mathrm{AFt}$
(6) $\mathrm{Ca}(\mathrm{OH})_{2}$

FIGURE 11: XRD results of Cr-contaminated soil stabilized with C6S24 under different numbers of wetting-drying cycles: (a) 0, (b) 3, and (c) 10.
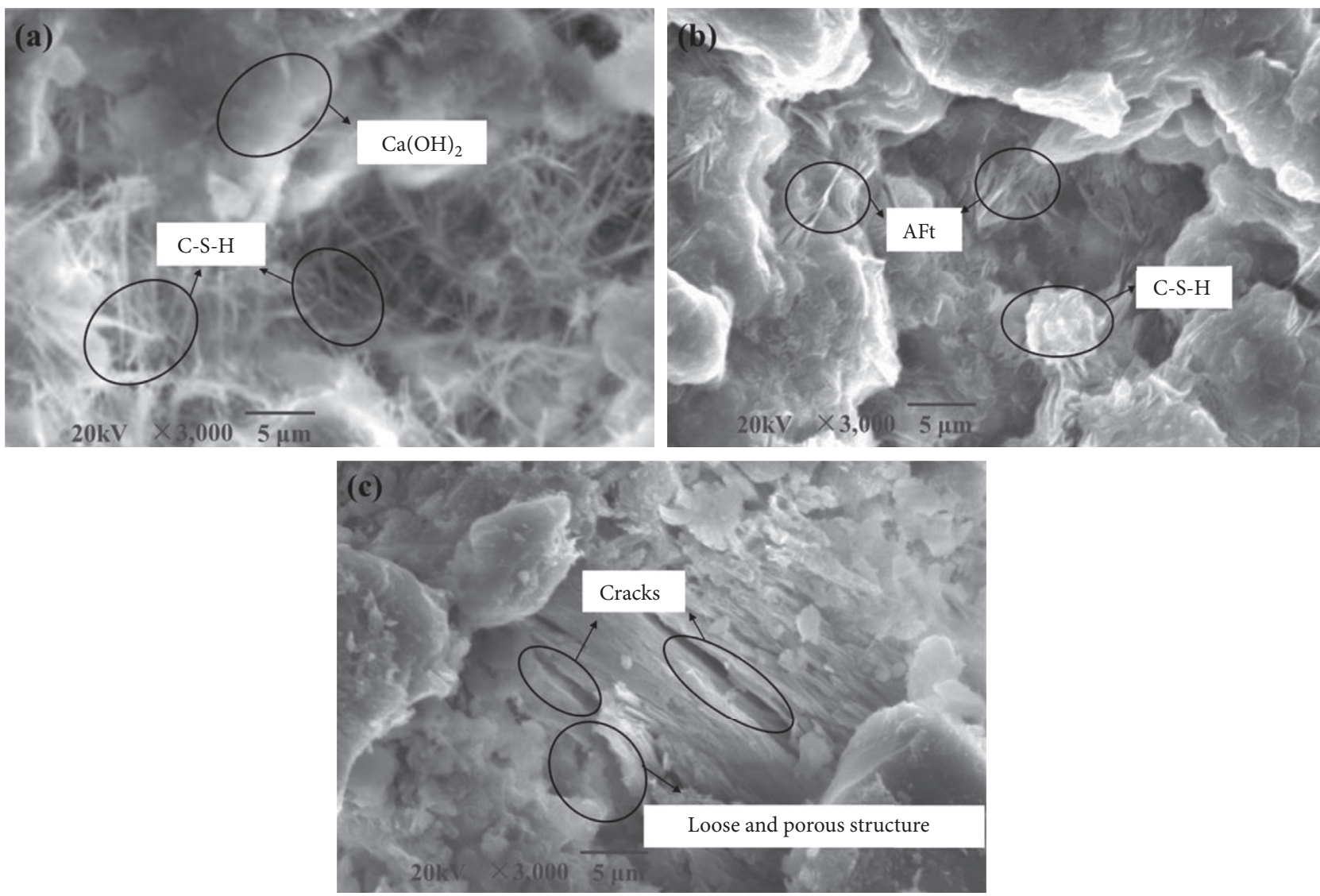

FIGURE 12: SEM results of Cr-contaminated soil stabilized with C6S24 under different numbers of wetting-drying cycles: (a) 0, (b) 3, and (c) 10.

with water, which led to the release of more $\mathrm{Cr}^{3+}$ of stabilized soils $[36,46]$. Moreover, the acidic leachate used in TCLP potentially disrupted the $\mathrm{pH}$ balance of the treated Crcontaminated soil, increasing the leachability of $\mathrm{Cr}^{3+}$.
3.4. Microstructure Characteristics. The mineralogical compositions of the Cr-contaminated soil treated with C6S24 after 0, 3, and 10 wetting-drying cycles determined using XRD technology are presented in Figure 11. As shown 
in Figure 11(a), the primary reactions products detected in the specimen included C-S-H, C-A-H, AFt, and $\mathrm{Ca}_{2} \mathrm{Cr}(\mathrm{OH})_{7} \cdot 3 \mathrm{H}_{2} \mathrm{O}$ under 0 wetting-drying cycles, which confirmed the increase of UCS and reduction of leachability of $\mathrm{Cr}^{3+}$ of contaminated soils treated by cement/soda residue. Additionally, it could be observed that some $\mathrm{Cr}^{3+}$ could exist as insoluble hydroxide nitrate complexes precipitation of $\mathrm{Ca}_{2} \mathrm{Cr}(\mathrm{OH})_{7} \cdot 3 \mathrm{H}_{2} \mathrm{O}$ in stabilized soils. The curve in Figure 11(b) shows that the peak intensity of C-S-H and AFt increased after 3 wetting-drying cycles. This result confirmed that the physicochemical reactions of cement/soda residue proceed during the initial wetting-drying cycles. While for the stabilized soils after 10 wetting-drying cycles presented in Figure 11(c), the peak intensity of C-S-H and AFt significantly decreased, which indicated that physicochemical reactions tended to fade and the products gradually dissolved out of soils. These results led to decrease of soil strength and increase of released $\mathrm{Cr}^{3+}$, which were consistent with the previous researches shown in Figures 8 and 10.

For further investigation of the micromorphology of the stabilized Cr-contaminated soils under cyclic wetting and drying, the photomicrographs were determined by SEM technology presented in Figure 12. As shown in Figure 12(a), a large amount of fibrous $\mathrm{C}-\mathrm{S}-\mathrm{H}$ and $\mathrm{Ca}(\mathrm{OH})_{2}$ was presented in the cement/soda residue stabilized soils after 0 wettingdrying cycles. The hydration and pozzolanic reactions were fully developed after curing for 90 days, and its products like C-S-H, C-A-H, and AFt could cement the soil particles and immobilize $\mathrm{Cr}^{3+}$, thereby increasing the soil strength and decreasing the leachability of $\mathrm{Cr}^{3+}$. For the stabilized soil after 3 wetting-drying cycles presented in Figure 12(b), some C-S-H and AFt was also observed and occupied the soil pore space in stabilized soil, which resulted in a denser soil structure. While for the stabilized soils after 10 wettingdrying cycles presented in Figure 12(c), it could be observed that numerous pores, localized cracks and loosened soil structure were formed in the soil. The structures of the stabilized soil deteriorated with the increase of wettingdrying cycles, which resulted in the decrease of soil strength and increase of leachability of $\mathrm{Cr}^{3+}$. This finding suggests that the variations in the leaching behavior of $\mathrm{Cr}^{3+}$ are closely associated with changes to the pore structure during the wetting-drying cycles, which is supported by the results shown in Figures 8 and 10.

\section{Conclusions}

The strength and leaching characteristics, as well as the longterm effectiveness under wetting-drying cycles of solidified/ stabilized Cr-contaminated soils treated by cement/soda residue, were comprehensively investigated in this study. Additionally, microcosmic testing techniques of XRD and SEM were used to determine the reaction mechanism. The main conclusions are drawn as follows:

(1) The UCS increased and the leached $\mathrm{Cr}^{3+}$ concentration decreased with curing time, binder content, and binder ratio, which confirmed the effectiveness of cement/soda residue on the remediation of $\mathrm{Cr}$ - contaminated soils. Increasing the soda residue from C6S14 to C6S24 could improve the soil UCS and reduce the leachability of $\mathrm{Cr}^{3+}$.

(2) The UCS decreased and leached $\mathrm{Cr}^{3+}$ concentration increased with increasing initial $\mathrm{Cr}^{3+}$ concentration of stabilized contaminated soils.

(3) The UCS increased and followed by a decrease with wetting-drying cycles of stabilized $\mathrm{Cr}$-contaminated soils. For the specimens of C6S14 and C6S24, the maximum UCS of $6.04 \mathrm{MPa}$ and $6.48 \mathrm{MPa}$ could be reached after 3 wetting-drying cycles, respectively. The UCS of stabilized soils was larger than $0.35 \mathrm{MPa}$ after 20 wetting-drying cycles, which satisfied the United States' strength standards for the remediation of landfills.

(4) The leached $\mathrm{Cr}^{3+}$ concentration decreased and followed by an increase with wetting-drying cycles of stabilized $\mathrm{Cr}$-contaminated soils. For the specimens of C6S14 and C6S24, the minimum leached $\mathrm{Cr}^{3+}$ concentrations of $2.78 \mathrm{mg} / \mathrm{L}$ and $1.93 \mathrm{mg} / \mathrm{L}$ could be reached after 3 wetting-drying cycles, respectively. The leached $\mathrm{Cr}^{3+}$ concentration of stabilized soils was below $5 \mathrm{mg} / \mathrm{L}$ after 0,3 , and 5 wetting-drying cycles, which satisfied the US EPA's evaluation criteria for the remediation of waste sites.

(5) Microstructure analysis results indicated that reactions products like C-S-H and AFt increasingly occupied the soil pore space and caused a denser soil structure in stabilized soil after 3 wetting-drying cycles. While after 10 wetting-drying cycles, the C-S$\mathrm{H}$ and AFt significantly decreased; numerous pores and localized cracks formed, which led to the deterioration of the soil structures.

\section{Data Availability}

The data used to support the findings of this study are available from the corresponding author upon request.

\section{Conflicts of Interest}

The authors declare that there are no conflicts of interest regarding the publication of this paper.

\section{Acknowledgments}

This work was financially supported by the Natural Science Foundation of China (Grant nos. 41672306, 41877262, 41807239, and 41372281), the Natural Science Foundation of Anhui Province, China (1908085 QD168), and the Special Project for Major Science and Technology in Anhui Province, China (18030801103).

\section{References}

[1] A. Facchinelli, E. Sacchi, and L. Mallen, "Multivariate statistical and GIS-based approach to identify heavy metal sources in soils," Environmental Pollution, vol. 114, no. 3, pp. 313-324, 2001. 
[2] C. Tang, B. Shi, W. Gao, F. Chen, and Y. Cai, "Strength and mechanical behavior of short polypropylene fiber reinforced and cement stabilized clayey soil," Geotextiles and Geomembranes, vol. 25, no. 3, pp. 194-202, 2007.

[3] E. Solgi, A. Esmaili-Sari, A. Riyahi-Bakhtiari, and M. Hadipour, "Contamination of metals in the three industrial estates, Arak, Iran," Bulletin of Environmental Contamination and Toxicology, vol. 88, pp. 643-638, 2012.

[4] J. J. Liu, F. S. Zha, L. Xu, Y. F. Deng, and C. F. Chu, "Engineering properties of heavy metal contaminated soil solidified/stabilized with high calcium fly ash and soda residue," in Proceedings of GeoShanghai 2018 International Conference: Geoenvironment and Geohazard, Springer, Singapore, 2018.

[5] C. Yu, A. Deng, J. Ma, X. Cai, and C. Wen, "Semi-analytical solutions for two-dimensional convection-diffusion-reactive equations based on homotopy analysis method," Environmental Science and Pollution Research, vol. 25, no. 34, pp. 34720-34729, 2018.

[6] C.-Y. Yin, H. B. Mahmud, and M. G. Shaaban, "Stabilization/ solidification of lead-contaminated soil using cement and rice husk ash," Journal of Hazardous Materials, vol. 137, no. 3, pp. 1758-1764, 2006.

[7] S.-J. Feng, S.-F. Lu, Z.-M. Shi, and W.-H. Shui, "Densification of loosely deposited soft soils using the combined consolidation method," Engineering Geology, vol. 181, pp. 169-179, 2014.

[8] Z. Zhang, G. Guo, Y. Teng et al., "Screening and assessment of solidification/stabilization amendments suitable for soils of lead-acid battery contaminated site," Journal of Hazardous Materials, vol. 288, pp. 140-146, 2015.

[9] Z. Li, C. Suo, X. Dong, and Y. F. Chen, "Experimental study on solidification of $\mathrm{Cu}(\mathrm{II})$-contaminated soil using red mud with cement and $\mathrm{Ca}(\mathrm{OH})_{2}$," Materials Testing, vol. 60, no. 2, pp. 184-190, 2018.

[10] Z. Shen, F. Jin, D. O'Connor, and D. Hou, "Solidification/ stabilization for soil remediation: an old technology with new vitality," Environmental Science \& Technology, vol. 53, no. 20, pp. 11615-11617, 2019.

[11] T. Singh and K. Pant, "Solidification/stabilization of arsenic containing solid wastes using portland cement, fly ash and polymeric materials," Journal of Hazardous Materials, vol. 131, no. 1-3, pp. 29-36, 2006.

[12] M. Dalmacija, M. Prica, B. Dalmacija, S. Roncevic, and M. Klasnja, "Quantifying the environmental impact of as and Cr in stabilized/solidified materials," Science of The Total Environment, vol. 412-413, pp. 366-374, 2011.

[13] J. J. Liu, F. S. Zha, L. B. Wang, and X. Q. Zhang, "Leaching properties of lead contaminated soils treated by soda residue," Journal of Southeast University, vol. 46, no. 1, pp. 94-98, 2016, in Chinese.

[14] L. Chen, S. Y. Liu, Y. J. Du, and F. Jin, "Strength comparison of cement solidified/stabilized soils contaminated by lead and copper," in Proceedings of the Geoenvironmental Engineering and Geotechnics, Shanghai, China, June 2010.

[15] Y. J. Du, N. J. Jiang, and L. Wang, "Study on strength and microscopic characteristics of cement-solidified zinc-contaminated kaolin soils," Chinese Journal of Geotechnical Engineering, vol. 34, no. 11, pp. 2114-2120, 2012, in Chinese.

[16] F. S. Zha, L. Xu, and K. R. Cui, "Study on strength characteristics of heavy metal contaminated soils solidified/stabilized by cement," Rock Soil Mech, vol. 33, no. 3, pp. 652-656, 2012, in Chinese.

[17] Y. Y. Li, S. W. Yan, J. Y. Zhang, and X. T. Yin, "Engineering properties and microstructural features of the soda residue,"
Chinese Journal of Geotechnical Engineering, vol. 21, no. 1, pp. 100-103, 1999.

[18] M.-X. Zhu, L. Lee, H.-H. Wang, and Z. Wang, "Removal of an anionic dye by adsorption/precipitation processes using alkaline white mud," Journal of Hazardous Materials, vol. 149, no. 3, pp. 735-741, 2007.

[19] G. Zhang, X. Li, Y. Li, T. Wu, D. Sun, and F. Lu, "Removal of anionic dyes from aqueous solution by leaching solutions of white mud," Desalination, vol. 274, no. 1-3, pp. 255-261, 2011.

[20] Y. B. Yang, M. R. Zheng, W. Y. Guo, and H. C. Wang, "Experimental research on the durability of inorganic binder stabilized material with soda residue," Key Engineering Materials, vol. 189-194, pp. 189-194, 2014.

[21] L. Zhao, B. Xu, G. Li, and J. Zhang, "Development status in comprehensive utilization of alkaline residues," Industrial Minerals and Processing, vol. 46, no. 6, pp. 76-79, 2017, in Chinese.

[22] ASTM D2216-10, Standard Test Methods for Laboratory Determination of Water (Moisture) Content of Soil and Rock by Mass, ASTM, West Conshohocken, PA, USA, 2010.

[23] ASTM D4318, Standard Test Methods for Liquid Limit, Plastic Limit, and Plasticity Index of Soils, ASTM International, West Conshohocken, PA, USA, 2010.

[24] ASTM D2487, Standard Practice for Classification of Soils for Engineering Purposes (Unified Soil Classification System), ASTM (American Society for Testing and Materials), West Conshohocken, PA, USA, 2011.

[25] ASTM D698, Standard Test Methods for Laboratory Compaction Characteristics of Soil Using Standard Effort, ASTM (American Society for Testing and Materials), West Conshohocken, PA, USA, 2012.

[26] J. Liu, F. Zha, L. Xu, C. Yang, C. Chu, and X. Tan, "Effect of chloride attack on strength and leaching properties of solidified/stabilized heavy metal contaminated soils," Engineering Geology, vol. 246, pp. 28-35, 2018.

[27] J. Liu, F. Zha, L. Xu et al., "Mechanism of stabilized/solidified heavy metal contaminated soils with cement-fly ash based on electrical resistivity measurements," Measurement, vol. 141, pp. 85-94, 2019.

[28] ASTM D2166-06, Standard Test Method for Unconfined Compressive Strength of Cohesive Soil, American Society for Testing Materials, West Conshohocken, PA, USA, 2006.

[29] U. S. EPA, "Method 1311: toxicity characteristic leaching procedure," in EPA SW-846: Test Methods for Evaluating Solid Waste, Physical/chemical Methods, Environmental Protection Agency, Washington, DC, USA, 3rd edition, 1994.

[30] ASTM D4843-88, Standard Test Method for Wetting and Drying Test of Solid Wastes, ASTM, West Conshohocken, PA, USA, 2016.

[31] Guide to the Disposal of Chemically Stabilized and Solidified Waste. Tratamento Físico-Químico, 1982.

[32] UK Environment Agency, Review of Scientific Literature on the Use of Stabilisation/solidification for the Treatment of Contaminated Soil, Solid Waste and Sludges, UK Environment Agency, Bristol, UK, 2004.

[33] D. L. Cocke, "The binding chemistry and leaching mechanisms of hazardous substances in cementitious solidification/ stabilization systems," Journal of Hazardous Materials, vol. 24, no. 2-3, pp. 231-253, 1990.

[34] F.-s. Zha, J.-j. Liu, L. Xu, and K.-r. Cui, "Effect of cyclic drying and wetting on engineering properties of heavy metal contaminated soils solidified/stabilized with fly ash," Journal of Central South University, vol. 20, no. 7, pp. 1947-1952, 2013. 
[35] Y.-S. Wang, J.-G. Dai, L. Wang, D. C. W. Tsang, and C. S. Poon, "Influence of lead on stabilization/solidification by ordinary Portland cement and magnesium phosphate cement," Chemosphere, vol. 190, pp. 90-96, 2018.

[36] D. Dermatas and X.. ,G. Meng, "Utilization of fly ash for stabilization/solidification of heavy metal contaminated soils," Engineering Geology, vol. 70, no. 3-4, pp. 377-394, 2003.

[37] O. E. Omotoso, D. G. Ivey, and R. Mikula, "Containment mechanism of trivalent chromium in tricalcium silicate," Journal of Hazardous Materials, vol. 60, no. 1, pp. 1-28, 1998.

[38] A. Kindness, A. Macias, and F. P. Glasser, "Immobilization of chromium in cement matrices," Waste Management, vol. 14, no. 1, pp. 3-11, 1994.

[39] A. Macias, A. Kindness, and F. P. Glasser, "Impact of carbon dioxide on the immobilization potential of cemented wastes: chromium," Cement and Concrete Research, vol. 27, no. 2, pp. 215-225, 1997.

[40] C. Y. Jing, S. Liu, G. P. Korfiatis, and X. G. Meng, "Leaching behavior of $\mathrm{Cr}$ (III) in stabilized/solidified soil," Chemosphere, vol. 64, no. 3, pp. 0-385, 2006.

[41] Q. Y. Chen, C. D. Hills, M. Tyrer, I. Slipper, H. G. Shen, and A. Brough, "Characterisation of products of tricalcium silicate hydration in the presence of heavy metals," Journal of Hazardous Materials, vol. 147, no. 3, pp. 817-825, 2007.

[42] C. Jing, X. Meng, and G. Korfiatis, "Lead leachability in stabilized/solidified soil samples evaluated with different leaching tests," Journal of Hazardous Materials, vol. 114, no. 1-3, pp. 101-110, 2004.

[43] A. C. Sophia, S. Sandhya, and K. Swaminathan, "Solidification and stabilization of chromium laden wastes in cementitious binders," Current Science, vol. 99, pp. 365-369, 2010.

[44] H. G. Mcwhinney and D. L. Cocke, "A surface study of the chemistry of zinc, cadmium, and mercury in Portland cement," Waste Management, vol. 13, no. 2, pp. 117-123, 1993.

[45] M. S. Y. Bhatty, "Fixation of metallic ions in Portland cement," in Proceedings of 4th National Conference on Hazardous Wastes and Hazardous Materials, pp. 140-145, Hazardous Materials Control Research Institute, Washington, DC, USA, 1987.

[46] X. Q. Zhang, Research on Stability of Soda Residue Solidified/ stabilized Heavy Mental Contaminated Soils under WettingDrying Cycles, Hefei University of Technology, Hefei, China, 2017, in Chinese. 